\title{
Similarity and Diversity in Macrophage Activation by Nematodes, Trematodes, and Cestodes
}

\author{
Stephen J. Jenkins and Judith E. Allen \\ Institute of Immunology \& Infection Research, University of Edinburgh, Edinburgh EH9 3JT, UK \\ Correspondence should be addressed to Judith E. Allen, j.allen@ed.ac.uk \\ Received 15 September 2009; Accepted 7 October 2009 \\ Academic Editor: Luis I. Terrazas
}

Copyright ( $) 2010$ S. J. Jenkins and J. E. Allen. This is an open access article distributed under the Creative Commons Attribution License, which permits unrestricted use, distribution, and reproduction in any medium, provided the original work is properly cited.

\begin{abstract}
This review summarizes current knowledge of macrophages in helminth infections, with a focus not only on delineating the striking similarities in macrophage phenotype between diverse infections but also on highlighting the differences. Findings from many different labs illustrate that macrophages in helminth infection can act as anti-parasite effectors but can also act as powerful immune suppressors. The specific role for their alternative (Th2-mediated) activation in helminth killing or expulsion versus immune regulation remains to be determined. Meanwhile, the rapid growth in knowledge of alternatively activated macrophages will require an even more expansive view of their potential functions to include repair of host tissue and regulation of host metabolism.
\end{abstract}

\section{Introduction}

Since the discovery in the late 1980s that T helper cells exhibit distinct cytokine profiles, the unique immunological profile associated with helminth infection has been explained by the activation of the Th2 cell pathway. In particular, the dramatic increase in numbers of eosinophils, mast cells, and IgE could be directly explained by cytokines produced by the Th2 subset. More recently, we have come to appreciate that in addition to eosinophils and mast cells, "alternativelyactivated" macrophages (AAM $\Phi)$ are a characteristic feature of the polarized Th2 response. Macrophages at helminth infection sites were termed AAM $\Phi$ because they exhibited specific characteristics, such as arginase 1 production, that had been observed when macrophages were exposed in vitro to IL-4 [1-3]. Siamon Gordon and colleagues described this as an alternative activation pathway that contrasted with the "classical" activation by LPS and IFN $\gamma[4,5]$. With further exploration of the in vivo phenotype, it has become apparent that $\mathrm{AAM} \Phi$ express a whole range of molecules that distinguish them from classically activated macrophages (САMФ) [6-9].

What has been remarkable is the consistency of the findings between the diverse laboratories and infectious models in which these cells have been studied, with identification of the same key molecules (arginase 1, resistinlike molecule [RELM] $\alpha, Y m 1$, etc.) expressed during helminth infection (see table in Reyes \& Terrazas review [10]). This is remarkable because "helminths" represent an enormously diverse range of pathogens with entirely different phylogenetic origins and life histories. Indeed, the AAM $\Phi$ phenotype seems to occur in any strong Th2 environment including allergy and some chronic microbial infections [10-12]. The commonality of these finding has, perhaps erroneously, suggested to us that we could define a broad function for these cells analogous to microbial killing for САМФ. However, despite an ever-broadening definition of ААM $\Phi$ and their associated markers and characteristics, we are still essentially ignorant of their in vivo function. Perhaps it is time to explore the many differences between the models used to study AAM $\Phi$ and consider that these cells may function differently depending on context.

\section{Helminths and Th2 Immunity}

2.1. Helminth Phylogeny. Helminth parasites are routinely used as models to study $\mathrm{T}$ helper cell polarization and 
as a result, our understanding of Th2 subset development and control has become increasingly sophisticated [1317]. However, it is important to appreciate that to draw broad conclusions from experiments with schistosomes and then apply these to nematode parasites (or vice versa), is potentially misleading. Despite the common terminology, the only shared biological features of many "helminthes" are their metazoan origins and the ability to infect mammals. Schistosomes are part of the platyhelminths that include the cestodes (tapeworms) and other trematodes (flukes or flatworms). The phyla Nematoda (roundworms) include hookworms, whipworms, and filarial parasites. The split that led to Platyhelminthes and Nematoda occurred over 1 billion years ago, long predating the split between vertebrates and invertebrates [18]. Nematodes are the most abundant animal on earth both in terms of total numbers and numbers of species. Within this group of animals, parasitism has independently evolved many times [19] and parasitic nematodes represent an enormous burden in terms of human, animal, and even plant health. In terms of human disease, platyhelminths infect fewer numbers but are responsible for higher levels of morbidity and mortality [20].

2.2. Th2-Biased Immunity. The utility of helminths as models to study Th subset bias stems from the striking feature that, despite their phylogenetic diversity, they all induce profound Th2 responses, characterized by CD4 $+\mathrm{T}$ cells producing IL-4, IL-5, IL-9, IL-10, and IL-13 among others. However, recently it has become apparent that even the Th2 subset itself is enormously complex, with $\mathrm{T}$ cells that specifically function to provide B cell help and produce IL-4 but not the other signature Th2 cytokines (follicular helper cells) [15], specific IL-9 producing cells [21], and other T helper subsets that produce Th2 cytokines such as the recent discovery that IL-10 is produced by Th1 cells [22]. In an adaptive immune response, macrophages ultimately respond to $\mathrm{T}$ cell derived cytokines, and a sustained alternative activation phenotype absolutely requires $\mathrm{CD} 4+\mathrm{Th} 2$ cells [23]. Thus, differences in Th cell cytokine profiles in different tissues and in response to distinct parasites will determine differences in macrophage activation.

2.3. Nematodes, Trematodes, and Cestodes and the Induction of the Th2 Response. Although virtually all helminths induce Th2 cytokines, the pattern and magnitude of these responses differ widely due to not only the vast differences in the biology of the pathogens as mentioned above, but also their broadly different migration and eventual host niche. Nematodes typically drive strong type 2 cytokine responses from the onset of infection. Indeed, within hours of infection innate activation of the Th2 pathway can be detected [2326]. However, even within the nematode phyla the intensity of this early type 2 response varies, perhaps reflecting the differential ability of nematodes to inhibit the type 1 inducing cytokine, IL-12 [27].

Eggs released by the schistosome parasites are believed to be the strongest known inducers of Th2 cytokines in mammals, and yet the invasive cercariae induces only a moderate Th2 response that is matched by a Th1 response of similar magnitude [28]. This initial mixed response is swamped by the extraordinarily high $\mathrm{Th} 2$ response generated to the eggs produced when the adult pairs reach sexual maturity [29]. Because of its importance as a cause of human morbidity and the availability of excellent mouse models, far more is known about the immunology of schistosome infection than other trematodes. However, Fasciola hepatica, a liver fluke that predominantly infects sheep and cattle, has also been studied in mouse models. Consistent with indicators of type 2 immunity in cattle, F. hepatica infection of mice results in a dominant Th2 response that has the capacity to suppress Th1 responses [30].

Cestodes are also dramatically understudied despite their capacity to cause severe disease in animals and people. Nonetheless, the data is consistent with the general helminth literature in that cestodes by and large have a strong propensity to drive Th2 immune responses. Similar to responses to schistosomes, peritoneal implantation of $\mathrm{BALB} / \mathrm{c}$ mice with Taenia crassiceps metacestodes results in an initially weak mixed Th1/Th2 response that becomes strongly Th2 dominated as infection progresses to the chronic phase [31, 32]. However, there are resistant mouse strains that expel the parasite in the acute phase due to the dominance of IFN $\gamma$ production [33]. Reponses to peritoneal infection with Echinococcus granulosus protoscoleces are unusual in that the initial Th2 responses that dominate early (week 1) become more mixed, with emergence of IFN $\gamma$ production as infection progresses (week 4) [34].

\subsection{Protective Immunity against Nematodes, Trematodes, and} Cestodes. In addition to the differences in the kinetics and magnitude of Th2 induction, the role of Th2 immunity in host protection varies substantially between these different parasites. Indeed, the paradigm that Th2 immunity is acting to destroy or expel worms is by no means universal.

The scenario in which there is an absolute requirement for Th2 immunity in host protection is that of the gastrointestinal nematodes. Expulsion of all GI nematodes studied to date is exquisitely dependent on Th2 cells. However, the specific cytokines (IL-4, IL-5, IL-9, IL-10, IL-13 among others) and the effector cells on which they act (epithelial, smooth muscle, mast cell, macrophage, nerve) vary tremendously depending on the location of the parasite, as well as its invasive properties. The situation with nematodes, such as the filariae, that live entirely in the tissues is somewhat different. Although Th2 responses are required for worm killing [35], Th1 immunity and particularly IFN $\gamma$, rather than inhibiting the anti-parasite Th2 response, act synergistically with IL-5 to kill the adult stage of the parasite [36]. In the case of these tissue-dwelling nematodes, our increased understanding of the cytokine pathways required for parasite destruction has still left us in the relative dark as to the actual killing mechanism(s).

During schistosome infection, Th2 responses are essential for host survival but this has little to do with detrimental effects on the parasite. This is largely due to the fact that pathology is the result of the egg deposition stage and 
it appears that in the absence of a Th2 response (or a Th1 response for that matter), the egg is highly tissue destructive. Death can occur either due to overwhelming gut inflammation and sepsis or liver damage [37]. Additionally, Th2 responses to the egg promote fibrosis that itself can be a major cause of morbidity [38].

Cestodes provide an unusual perspective, in that despite inducing a potent Th2 response, protective immunity can require Th1 cells $[33,39]$. Indeed, dominance of Th2 responses during infection with $T$. crassiceps leads to susceptibility to infection mainly through the suppression of Th1driven nitric oxide (NO) production, a key effector molecule against these parasites [32, 39]. However, cestodes are also unusual in that there is little consistency in immunological mechanisms that protect against infections within this group. In this respect, resistance to E. granulosus actually increases in the absence of NO production [40], possibly due to the absence of the considerable suppressive effects on proliferation that this molecule exerts in echinococcosis [41].

\section{The Molecular Profile of AAM $\Phi$}

AAM $\Phi$ are becoming increasingly recognised as a key effector arm of the Th2 immune response, but their actual function in different helminth infections has yet to be unravelled (see below) and is likely to be as diverse as the role of Th2 immunity itself. The concept of "alternative macrophage activation" was introduced by Siamon Gordon and colleagues in the early 1990s to describe the in vitro response of macrophages to the Th2 cytokines IL-4 and IL-13 [4, 5]. Significantly, the term AAM $\Phi$ was coined to highlight the activated nature of these cells that distinguished them not only from macrophages classically activated by microbial products and Th1 cytokines (CAM $\Phi)$, but from deactivated macrophages in which costimulatory molecules and class II expression are suppressed by down-regulatory cytokines such as IL-10. The two features that distinguished AАM $\Phi$ in vitro were the expression of arginase 1 and the mannose receptor. The requirement for IL-4 and/or IL-13 was subsequently confirmed in vivo, using gene-deficient mice $[6,11,42,43]$.

Realization that the AAM $\Phi$ described in vitro were a feature of helminth infection came from studies of Schistosoma mansoni and Brugia malayi $[6,43]$. Both studies verified IL4 dependent arginase 1 expression by macrophages in vivo, but the B. malayi study additionally identified novel IL-4 dependent genes associated with this phenotype including Ym1 and RELM $\alpha /$ FIZZ1 [6]. The highly unique profile was rapidly confirmed across the full range of helminth infections $[7,44-48]$. Although Ym1 and RELM $\alpha$ were discovered in vivo, the direct induction of these genes by IL- 4 and/or IL-13 was also demonstrated in vitro $[2,3]$. It should be noted here that IL- 4 and IL-13 both utilize the same signal transducing receptor chain, the IL-4 receptor $\alpha$ (IL-4R $\alpha$ ), which explains the considerable overlap in function of these cytokines. Which of these cytokines is more important for alternative activation of macrophages in vivo remains to be fully determined, however, a recent report using mice deficient for the IL-13 receptor $\alpha 1$ subunit suggests that IL13 is dispensable for expression of Ym1 and RELM $\alpha$ but not arginase in the liver during $S$. mansoni infection [49].

A molecular signature for AAM $\Phi$ (defined here as an IL4/IL-13 dependent phenotype) has arisen that is represented by the three most abundant IL-4/IL-13 dependent gene products: $\mathrm{Ym} 1, \mathrm{RELM} \alpha$, and arginase $1 . \mathrm{Ym} 1$ is a member of the family 18 chitinases but has no chitinolytic activity and is thus referred to as a chitinase-like molecule [50]. Other members of this family in mice include $\mathrm{Ym} 2$ and acidic mammalian chitinase (AMCase), the later functioning as a true chitinase. Ym2 and AMCase are also IL-4/IL-13 inducible proteins and the similarity between $\mathrm{Ym} 1$ and $\mathrm{Ym} 2$ is so high that most studies do not actually distinguish between them. All antibodies to date recognize both, and most PCR methods do not distinguish them, although this is possible with careful primer design. Thus, unless a study clearly identifies a specific Ym protein, it might be appropriate to use the more ambiguous designation $\mathrm{Ym} 1 / 2$. RELM $\alpha$ was first described in a lung asthma model, where it was described as FIZZ1 [51], but was subsequently identified as a member of a family of cysteine-rich molecules related to resistin, a hormone involved in glucose metabolism [52]. Arginase 1 is the best studied of these proteins and has wellestablished roles in regulating NO production by competing with iNOS for their common substrate L-arginine [1], as well as inhibition of $\mathrm{T}$ cell responses through $\mathrm{L}$-arginine depletion [53]. The arginase pathway additionally leads to the production of proline and polyamines, which contribute to tissue repair and fibrosis [54]. Subsequently there has been identification of numerous other markers associated with the alternative activation phenotype $[7,9]$ and this number is likely to grow as more extensive transcriptomic and proteomic analyses are undertaken [55].

Macrophages with an AAM $\Phi$ phenotype characterized mainly by arginase 1 production also arise in protozoan (reviewed in [10]) and certain bacterial infections [56]. In cutaneous leishmaniasis (Leishmania major), this AAMФ phenotype is dependent on signaling through the IL$4 \mathrm{R} \alpha$ chain [57] as in helminth infection models $[6,11$, 42]. However, a STAT6-independent pathway also leads to arginase 1 expression during Mycobacterium tuberculosis and Toxoxplasma gondii infections, which in the former is dependent upon TLR signaling [56]. The main effect of arginase 1 expression in all of these settings appears to be an increase in susceptibility to infection through diversion of L-arginine from production of the reactive nitrogen intermediates that kill these pathogens $[10,56]$.

As interest in these cells grew, the term "alternativelyactivated" came to include any cell displaying an alternate phenotype to САMФ. Subdivision of the M1 and M2 terminology has helped to address this issue with M1 equating with $C A M \Phi$ while $M 2$ includes $M 2 a, M 2 b$, and M2c. M2a most closely reflects the IL-4/13 dependent phenotype originally associated with $\mathrm{AAM} \Phi$, while $\mathrm{M} 2 \mathrm{~b}$ includes activation by other modulators such as immune complexes that lead to high IL-10 production and M2c reflecting the more deactivated phenotype associated with IL-10 treatment in vitro [58]. Nonetheless, the difficulty in 

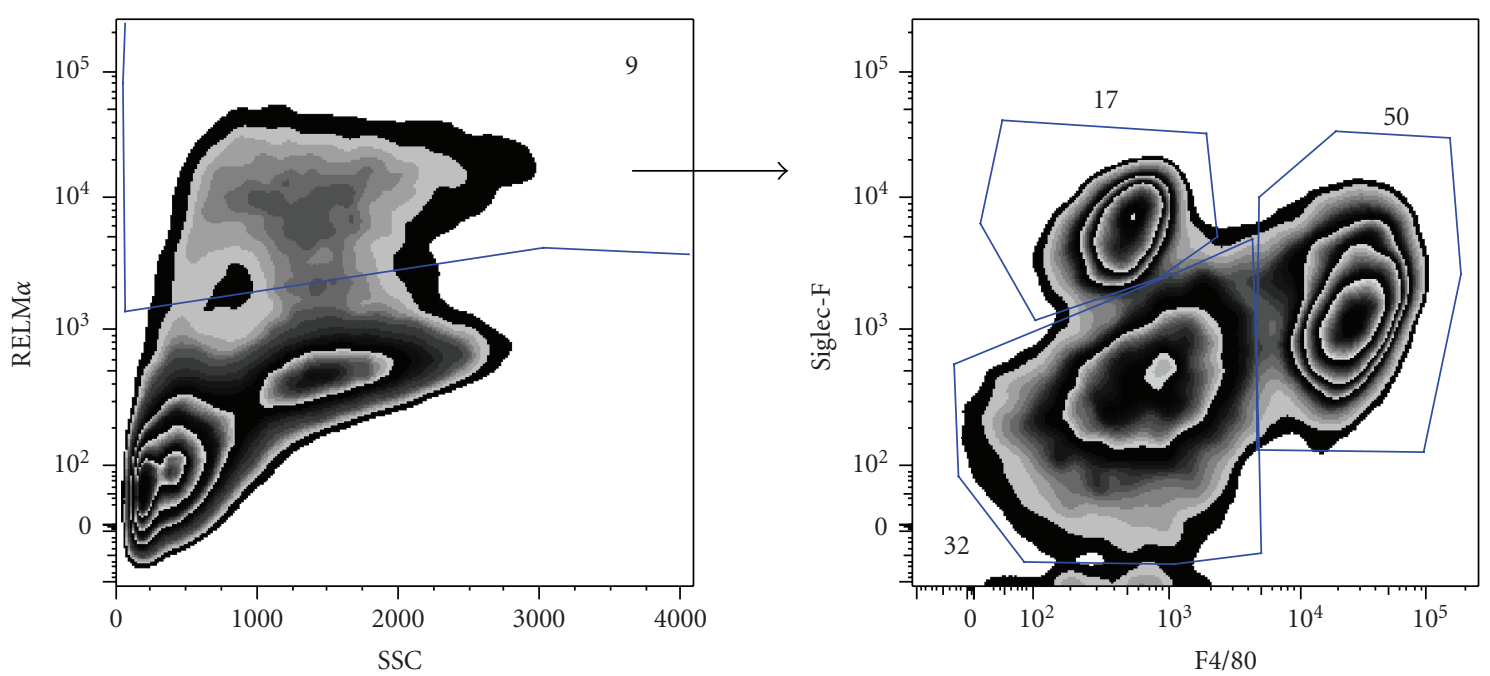

(a)
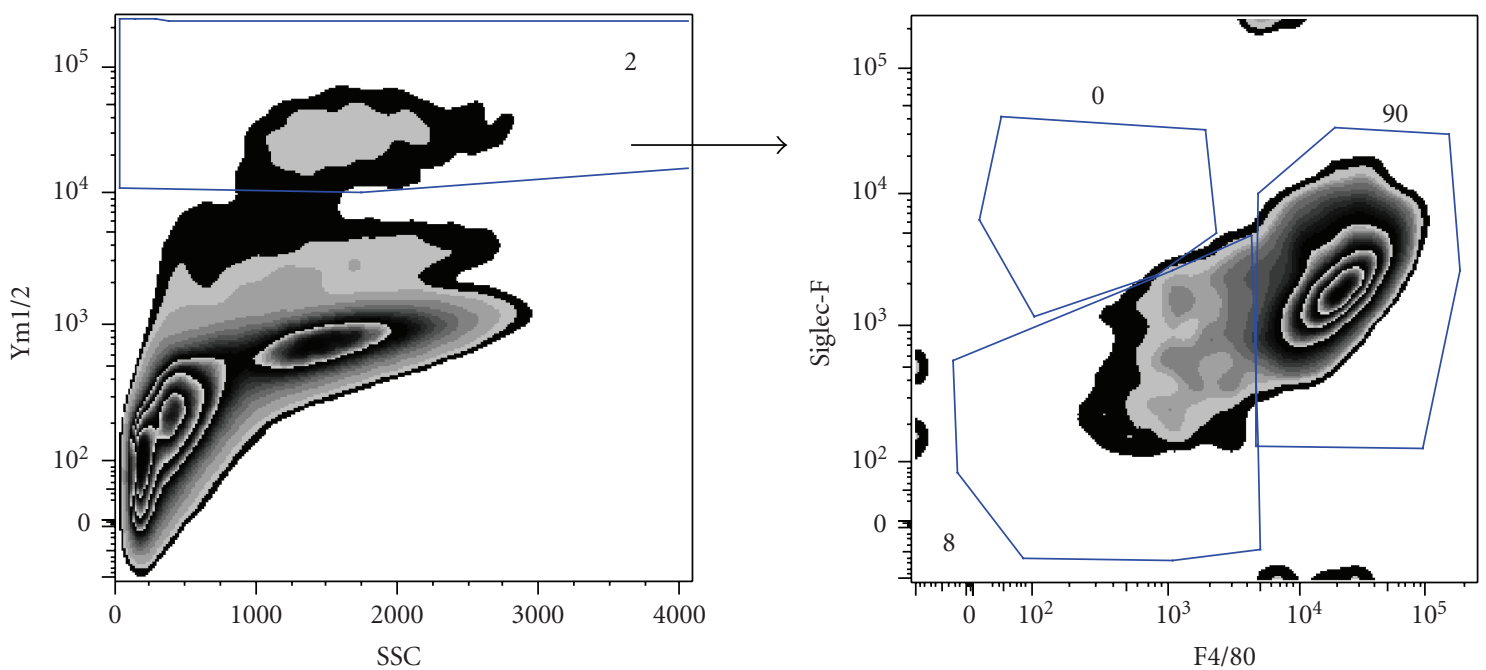

(b)

FIGURE 1: RELM $\alpha$ and YM1/2 expression in the pleural cavity during L. sigmondontis infection. Left-hand plots: Flow cytograms depicting side scatter (SSC) versus RELM $\alpha$ (a) or Ym1/2 (b) of pleural cavity cells 12 days post infection with L. sigmodontis. The gates for RELM $\alpha^{+}$ and $\mathrm{Ym} 1 / 2^{+}$cells were set using isotype control staining. The proportion of cells positive for RELM $\alpha$ and Ym1/2 in naïve mice was $1.5 \%$ and $0.05 \%$, respectively. Right-hand plots: Siglec-F versus F4/80 expression on Ym1/2+ or RELM $\alpha^{+}$cells. Numbers in italics represent percentage of cells within the neighbouring gate.

finding appropriate terms is a reflection of the enormous diversity in macrophage phenotype found both in vivo and in vitro [59], as well as their capacity to rapidly alter their expression profile in response to a new set of environmental signals [60].

A current difficulty in delineating the functions of AAM $\Phi$ is that many of the "signature" AAM $\Phi$ molecules are not restricted to macrophages. The availability of good antibodies for intracellular staining and fluorescence microscopy, the creation of mice that report gene expression, and the ability to sort cell subsets prior to gene expression analysis have greatly increased our knowledge of the range of cells that show an "alternative-activation" phenotype, as well as the comparative breadth of expression of the different AAM $\Phi$ markers. For example, in liver granulomas from mice infected with S. mansoni, the main producer of RELM $\alpha$ appears to be eosinophils rather than macrophages [61], whilst in lung granulomas induced by i.v. injection of schistosome eggs, RELM $\alpha^{+}$cells are comprised of macrophages, eosinophils, and airway epithelial cells [62]. In the serous cavities of mice infected with Litomosoides sigmodontis or $B$. malay $i$, we have observed a similarly broad pattern of RELM $\alpha$ expression, with mature macrophages $\left(\mathrm{F} 4 / 80^{\mathrm{hi}}\right.$ Siglec- $\left.\mathrm{F}^{-}\right)$, eosinophils (Siglec- $\mathrm{F}^{\mathrm{hi}} \mathrm{F} 4 / 80^{\mathrm{lo}}$ ), and F4/80 $0^{\text {lo-intermediate }}$ Siglec$\mathrm{F}^{-}$cells that include $\mathrm{DC}$, all capable of making this protein (Figure 1(a) and data not shown). Expression of $Y m 1 / 2$ is 
markedly different, being almost exclusively restricted to $\mathrm{F} 4 / 80^{\mathrm{hi}}$ Siglec- $\mathrm{F}^{-}$mature macrophages (90\%), and with no expression detectable in eosinophils (Figure 1(b)). However, Ym1/2, like RELM $\alpha$ can also be expressed by epithelial cells in the lung $[61,63,64]$ and both Ym1/2 and RELM $\alpha$ appear to be a feature of many types of antigen presenting cell found in the lymph nodes draining helminth infection sites [46]. Thus, it is now apparent that many cell types can show an "alternative-activation" phenotype, with chitinaseand resistin-family members prominent. Epithelial cells in particular express not only Ym1/2 and RELM $\alpha$ during Th2 immune responses but related family members including the true chitinase, AMCase [63] and RELM $\beta$ [65]. Of the three most abundant $A A M \Phi$ markers [6], arginase 1 appears to have a more macrophage-restricted expression profile. This was demonstrated by Reese et al. using mice that contain an IRES-YFP knock-in allele that reports arginase 1 expression, in which extra-hepatic arginase 1 expression was macrophage-restricted in the lung or peritoneum of Nippostrongylus brasiliensis infected or chitin injected mice, respectively [66].

Another major difficulty has been efforts to translate our understanding of murine AAM $\Phi$ to humans, not only because some of the mouse defined AAM $\Phi$ markers are not present in the human genome, but because the relevant tissues cannot be readily accessed. An example of this problem has been the argument over whether human macrophages express arginase 1, strongly reminiscent of earlier arguments about NO production [67]. It may be that arginase 1 expression is more limited in human macrophages or that we have just not yet identified the right tissues. Indeed, arginase 1 can be induced in human macrophages by IL-4 [68] and can be observed in monocytes of filiarialinfected individuals [69].

Even more problematic has been the realization that $\mathrm{Ym} 1$ is not even present in the human genome. However, distribution of the family 18 chitinases (including AMCase and $Y m 1 / 2$ ) between different mammalian species is a fascinating puzzle in itself. Mammals have two genes encoding active chitinases that represent an ancient gene duplication event and show high sequence homology to chitinases of lower organisms. The mammalian chitinaselike proteins (CLPs) that include Ym1, appear to represent more recent gene duplication events with subsequent lossof-function mutations [70]. Thus all mammals express the highly conserved active enzymes, chitotriosidase and acidic mammalian chitinase (AMCase) but additionally express a broad range of diverse CLPs, with each mammalian species exhibiting a different complement of CLPs [70]. In mice these include Ym1, Ym2, and YKL-40/BRP-39, which have all been strongly implicated in Th2 conditions [50, 71]. Humans express YKL-40 but also a distinct CLP, YKL-39 [70]. Because no two mammals express the same set of these proteins and CLPs appear to be undergoing remarkably active evolution, no animal model can fully represent the human genes. Studying mice should nonetheless be informative as one can presume that despite species differences a common theme lies behind the evolutionary forces driving the divergence of CLPs.

\section{Functional Roles of $\operatorname{AAM} \Phi$}

As the molecular definition of $A A M \Phi$ becomes more refined, our hope has been that an understanding of function would follow. However, the functions of gene products associated with alternative activation, such as RELM $\alpha$ and Ym1 remain elusive and our full understanding of the contribution of macrophages during helminth infection is an increasingly active area of investigation. Considering the diversity of helminth infection and the complexity of the associated Th2 response, a single well-defined role for $\mathrm{AAM} \Phi$ is unlikely to emerge.

4.1. Do МФ Promote Helminth Killing or Expulsion? The depletion of macrophages using clodronate-loaded liposomes has provided a powerful tool by which to analyse the function of these cells during helminth infection. This technique has provided evidence that macrophages play a central role in nematode expulsion during intestinal infection, both in the memory response to a secondary infection with Heligmosomoides polygyrus [72], and in expulsion of primary $N$. brasiliensis infection [73]. In both these settings, parasite clearance is dependent upon a strong Th2 response, which acts to rapidly recruit immune cells including macrophages to the infection site and to stimulate their expression of Arginase 1, RELM $\alpha$, and Ym1/2 in a STAT- 6 dependent manner. Critically, blocking recruitment of macrophages via depletion of monocytes resulted in prevention of worm expulsion, whilst the Th2 response and recruitment of other inflammatory cell populations were left intact. Our understanding of macrophage function in filarial nematode attrition is more limited. However, observations that worm survival during murine peritoneal infection with either Brugia pahangi or malayi L3 larvae is enhanced following injection of carbon particles or carrageenan [74, 75] imply an effector function for peritoneal macrophages. Consistent with a role in filarial killing, macrophages make up significant proportion of the granulomas that encase dying $B$. malayi and L. sigmodontis worms but the conundrum is: do granulomas cause worm damage or form because the worms are already damaged?

While there is evidence for macrophage effector function during nematode infections, it is still unknown whether this occurs via direct or indirect mechanisms. Macrophages greatly increase the hypercontractility of intestinal smooth muscle during $N$. brasiliensis infection, providing a potentially indirect effector mechanism [73]. Because filarial nematodes are restricted to tissue sites during infection, it is likely a distinct though overlapping array of effector mechanisms is required to act against these nematodes. Perhaps a more likely role for macrophages in these infections is to recruit other Th2 effector cells important in nematode attrition. In this respect, eosinophils have a well-documented role in vivo, acting against larval stages of both $B$. malayi and L. sigmodontis $[76,77]$, and recent data demonstrates that recruitment of eosinophils to the peritoneal cavity following $N$. brasiliensis infection or injection of chitin is dependent on macrophages $[66,78]$. An attractive possibility for a direct anti-nematode effector function is the association of AAM $\Phi$ 
with chitinases and chitinase-like molecules [50], which in principle have the capacity to act on chitin-containing stages of the parasite. However, as of yet, there is no direct evidence to support this.

\subsection{Is Alternative Activation Required for Anti-Worm Effec-} tor Function? Whilst macrophages can perform as antinematode effector cells, the question remains whether they need to alternatively activate to exert this function. Anthony et al. , showed that, like macrophage depletion, an inhibitor of arginase, S-(2-boronethyl)-l-cysteine, could impair worm expulsion during secondary $H$. polygyrus infection [72]. Using the same technique, arginase I expression was also implicated as mediating expulsion of $N$. brasiliensis, although experiments were inconclusive since treatment only prevented worm expulsion in $60 \%$ of the mice despite parasite egg production and host smooth muscle hyper contractility being greatly impaired [73]. The broad-acting nature of this treatment (it blocks both arginase I and II and could potentially act directly on worms in addition to other non macrophage host cell sources) makes it hard to draw firm conclusions. A stronger case against alternative activation driving these macrophage effector mechanisms, is provided by two earlier studies both of which used mice on the same resistant BALB/c background as Zhao et al. [73]. These demonstrated that IL- $4 \mathrm{R} \alpha$ need not be expressed on macrophages/neutrophils or indeed any hematopoetic population in order for efficient expulsion of $N$. brasiliensis [79, 80]. Using the same macrophage/neutrophilspecific IL- $4 \mathrm{R} \alpha$-deficient mice, it has also been shown that alternative activation of macrophages is not required for expulsion of another intestinal nematode Trichinella spiralis [81]. Other potential effector functions of "Th2associated" macrophages may also be independent of alternative activation state, as for example, macrophagedependent-recruitment of eosinophils in response to chitin injection is STAT6-independent [66]. It is quite conceivable that in Th2 infections, macrophage effector function could be completely independent of AAM $\Phi$-associated molecules or that expression of arginase 1 or other AAM $\Phi$-associated molecules could be induced by an IL- $4 \mathrm{R} \alpha$-independent mechanism, for example via a TLR-dependent event $[10,56]$ such as exposure to gut flora. Unfortunately, the expression of either arginase 1 or other AAM $\Phi$ associated markers was not investigated in the intestinal tissues of $N$. brasiliensis or T. spiralis infected M $\mathrm{M} /$ neutrophil-specific IL- $4 \mathrm{R} \alpha$-deficient mice $[79,81]$. Comparative analysis of the susceptibly of mice which lack, in macrophages specifically, either IL$4 \mathrm{R} \alpha$ or "alternative activation" proteins such as arginase 1 would help considerably to resolve the issue of the function of alternative activation "per se" in intestinal nematode infections. Interestingly, a study with such mice has shown that arginase 1 expression by AAM $\Phi$ has no host protective effect against primary infection with the trematode $S$. mansoni [82].

4.3. Can CАМФ Act against Helminths? In contrast to the ambiguity surrounding alternative activation in immunity to nematodes, it is clear that the reactive oxygen or nitrogen species can damage most types of helminth parasites $[39,83-$ $86]$. However, only in cestode infection do reactive nitrogen species and САM $\Phi$ appear to function against the parasite in vivo. In murine cysticercosis ( $T$. crassiceps) blocking of iNOS using the inhibitor L-NG-monomethyl arginine leads to increased parasite burdens [39]. Consistent with this, induction of Th2 responses and STAT- 6 signaling underlie susceptibility to infection, whilst Th1 responses and STAT-4 signaling underlie resistance $[32,33]$. However, as mentioned above, this is not a requirement in immunity to all cestodes. Indeed, NOS2 deficient mice, which are incapable of making iNOS, are actually less susceptible to infection with the cestode parasite E. multilocularis [40]. In this infection САM $\Phi$ appear to have a pathological effect, most likely due to the direct immunosuppressive effect of NO on cell proliferation [87].

Given the divergence of the helminth parasite phyla and the host tissue sites they have chosen to infect, it is perhaps unsurprising that diverse effector mechanisms are required for immunity to different infections $[44,88]$. However, a common thread is that macrophages can act against both nematode and platyhelminth infections, and there is still no published evidence of any infection in which macrophages can be dispensed at no cost to resistance. The mechanisms employed by the macrophages though are seemingly disparate. As discussed below, AAM $\Phi$ do play an important role in protecting the host in schistosomiasis by limiting parasitemediated tissue damage rather than mediating killing [79]. Indeed as we struggle to identify direct antihelminth effects of $A A M \Phi$, the evidence builds that the macrophage products most associated with alternative activation such as arginase 1 and RELM $\alpha$ have profound inhibitory effects on host immunity, including the Th2 response itself $[61,62,82]$. This raises the possibility that the alternative activation state of macrophages does not function primarily as an effector arm but has critical regulatory or parasite disposal (rather than killing) roles.

4.4. ААМФ Are Potent Suppressors of Cellular Proliferation. One property of activated macrophages that is consistently observed in a wide variety of systems is the ability to block the proliferation of cells with which they are cocultured. This feature has been well described for CAM $\Phi$ in which the antiproliferative properties of NO are responsible [87]. Myeloid cells derived from helminth infected animals also exhibit similar antiproliferative properties [60, 89-91]. Importantly, it can be replicated in vitro by treatment of macrophages with IL-4 or IL-13 [2, 60] and in vivo is reliant on IL-4 and/or IL-13 in certain settings [89]. Indeed, the ability to inhibit cellular proliferation is a defining characteristic of $А A M \Phi$. Despite the near-universal finding that $\mathrm{AAM} \Phi$ suppress cellular proliferation ex vivo, the in vivo significance is not known. Understanding the relevance of this proliferative suppression has been complicated by the fact that, unlike $C A M \Phi$, a single mechanism for proliferative inhibition has not been identified. Instead a multitude of pathways have been found that differ depending on the infection context (reviewed in [44]) and include Programmed 
death ligand (PD-L) interactions [92, 93], TGF- $\beta$ production [94], lipid mediator release [95], IL-10 production [96, 97], and L-arginine depletion [82]. There appear to be three categories of proliferative suppression generally observed during helminth infection: contact and IL-4 dependent, contact dependent and IL-4 independent, and finally IL-4 dependent and contact-independent. No doubt the target cells will also differ depending on the pathways involved, with some mechanisms, such as the PD-L pathway seen during infection with the platyhelminths, $T$. crassiceps, and S. mansoni $[92,93]$, affecting predominantly $\mathrm{T}$ cells. Other mechanisms have a broader target including even tumor cells that typically have no restriction on cell division [89].

One cannot overemphasize the diversity of suppressive mechanisms observed. For almost every mediator identified as critical for $\mathrm{AAM} \Phi$-mediated suppression of $\mathrm{T}$ cells, there is another study that finds that mechanism dispensable. This disparity could be due to the distinct biological mediators released by these vastly different parasites, which presumably all favour an immuno-suppressive environment. However, many other factors could account for this diversity, from differences in the magnitude and bias of the Th cell response to tissue localization. Of interest, proliferative suppression is also a feature of myeloid-derived suppressor cells (MDSC), which share many features with АAM $\Phi$ but are associated with cancer and other immune suppressive environments rather than helminth infection [98]. T cell suppression by MDSC is mediated by both iNOS-driven production of $\mathrm{NO}$ and arginase 1-driven depletion of L-arginine [53]. Larginine is essential for $\mathrm{T}$ cell activation [99] but L-arginine depletion could also lead to production of suppressive reactive oxygen intermediates $[95,100]$. This is similar to recent data showing that macrophage-derived arginase 1 is required to suppress the proliferation of $\mathrm{T}$ cells from S. mansoni-infected mice [82] but also during non-healing Leishmania major infection, which is associated with AAM $\Phi$ [1]. Although arginase 1 is emerging as one of the most important mediators of proliferative suppression, it is not the full story. Chemical blockade of arginase 1 had only a small impact on suppression mediated by ААM $\Phi$ from the peritoneal cavity of $B$. malayi implanted mice, and full IL-4-dependent suppressive capacity was maintained when arginase expression was reduced by LPS/IFN $\gamma$ treatment [60].

Finally, it is important to consider that NO mediated suppression, although most strongly associated with microbial infection, also has a role to play during helminth infection. As already mentioned, NO can act as an effector molecule during infection with the cestode T. crassiceps [39]. However, within the same infection model [95], and infection with E. multilocularis [41], NO mediated suppression by peritoneal cells has been observed. Even in filariasis, where the IL-4 dependent AAM $\Phi$ suppressive phenotype has been well described, NO-mediated suppression can play a role [101].

4.5. АAMФ as Antigen Presenting Cells. In line with the immuno-suppressive effects of AAM $\Phi$ described above, one of the most consistent findings in human studies is that individuals infected with helminth parasites exhibit profound defects in lymphocyte proliferation [102-105]. One popular hypothesis has been that monocytes or macrophages from infected individuals were somehow defective in their antigen presentation capacity. However, as the discovery of alternative activation emerged and their capacity to actively block cellular proliferation was revealed the expectation shifted somewhat. Further, by definition $\mathrm{AAM} \Phi$ are activated and thus might be expected to express good levels of class II and costimulatory molecules. Not surprisingly, the analysis of macrophage APC activation state during helminthiases has been shown to vary considerably with infection. However, expression of antigen presentation-associated molecules is frequently intact or elevated, consistent with an "activation" profile. Mice carrying schistosome infections show marked up-regulation of MHCII but not CD80 or CD86 by splenic macrophages [93]. Transient up-regulation of co-stimulatory molecule and MHCII expression on lung macrophages occurs during the period $N$. brasiliensis larvae migrate through the lung but is quickly lost thereafter [106]. Following peritoneal implant of adult B. malayi, macrophages exhibit relatively high levels of MHCII, CD80, and CD86 expression compared to thioglycollate elicited $\mathrm{M} \Phi$, but not compared to LPS-stimulated cells [60]. Perhaps the strongest activation is seen in T. crassiceps infected mice, where MHCII, CD40, and CD86 but not CD80 are greatly up-regulated over an 8-week period [91]. However, this is by no means a feature of cestode infection, since the one documented parasitic helminth that leads to a reduction in activation state compared to naïve $\mathrm{M} \Phi$ is E. multilocularis although only expression of CD40 is reduced whilst CD80 and CD86 remained unchanged [107].

A number of labs have investigated $\mathrm{M} \Phi$ expression of B7 family members PD-L1 and PD-L2, with a diversity of findings in nematode, trematode, and cestode models. Independent of parasite species, Loke et al. defined PDL2 as a marker for $\mathrm{AAM} \Phi$, specifically up-regulated by IL-4 in a IL-4R $\alpha /$ STAT-6 dependent manner and PD-L1 as a Th1-associated ligand [108]. However, neither PD-L1 or PD-L2 are up-regulated on peritoneal AAM $\Phi$ elicited by the nematode $B$. malayi [60]. In contrast, both ligands are up-regulated in the lung following but not during $N$. brasiliensis larval migration [106]. Similar dichotomy exists in the response to platyhelminths, with only PD-L1 upregulation in response to S. mansoni infection [93], yet PDL1 and PD-L2 up-regulation in response to T. crassiceps [92]. Significantly in these two settings, PD-L1 and/or PD$\mathrm{L} 2$ act to potently block the proliferation of $\mathrm{T}$ cells and are thus at least in part responsible for the contact-dependent proliferative suppressive effect of AAMФ discussed above.

How then do AAM $\Phi$ perform as APC? Given that AAM $\Phi$ exhibit a profound ability to suppress cell division and fail to induce naïve T-cell proliferation, it was a surprise when initial experiments showed that $А A M \Phi$ from $B$. malayi infected mice were strong inducers of Th2 cytokine production when cocultured with naive T-cells [109]. This ability is also shared with AAM $\Phi$ from chronic late-stage T. crassiceps infection [91]. Interestingly, the capacity to 
drive Th2 cytokine production correlated with alternative activation, as adherent peritoneal cells from early-stage infection induce more of a mixed Th1/Th2 response while showing much lower expression of RELM $\alpha$ and Ym1/2 [91]. It remains to be determined whether the ability to drive Th2 cytokine production is a shared function of АAM $\Phi$ from all helminth infections. The difficulty in extracting $А A M \Phi$ in sufficient quantity from tissues, such as the gut lamina propria, has so far prohibited analysis of APC function in many settings, particularly intestinal infections.

It is tempting to draw a parallel to dendritic cells (DC) obtained from schistosome infected mice or exposed to helminth products in vitro. These exhibit a muted activation phenotype, with little change in expression of costimulatory molecules, and limited up-regulation of MHCII. However, they also efficiently promote Th2 polarisation and cytokine production [110-112]. Furthermore, DC can exhibit an alternative activation phenotype in vitro $[46,113]$ and during infection [46] or allergy [114], up-regulating expression of Ym1/2 and RELM $\alpha$ in an IL-4/IL-13 dependent manner $[46,113,114]$. Indeed, experiments looking at the ability of "alternatively activated" DC to drive Th2 responses in vitro and in vivo have identified $\mathrm{Ym} 1 / 2$ as a key molecule involved in the process $[113,114]$. Ym1/2 appears to exert this effect by binding to 12/15-lipoxygenase and blocking production of PPAR $y$ ligands [114], which are thought to have immunoregulatory effects on macrophages and T cells [115]. Given the large quantities of $\mathrm{Yml} / 2$ produced by AАM $\Phi$ it is quite possible they also influence Th2 priming via this molecule.

\section{6. $А A M \Phi$ as Negative Regulators of Th2 Immunity}

4.6.1. RELM $\alpha$. The discovery that two novel proteins (Ym1 and RELM $\alpha$ ) were secreted in abundance by macrophages activated during helminth infection [6] led rapidly to the speculation that these would be effector molecules against the metazoan invaders. This was supported by the realisation that $\mathrm{Ym} 1$ was a member of a family of chitinases with presumed defensive roles against chitin-containing pathogens such as nematodes. More direct (but still circumstantial) evidence came with the recognition that $\operatorname{RELM} \beta$, another resistin family member, was abundantly secreted by epithelial cells in the intestines of nematode infected mice and bound directly to the chemosensory structures of the parasite [65]. The expectation naturally followed that similar antiparasite roles would be identified for macrophage-derived RELM $\alpha$. However, two recent papers utilizing RELM $\alpha$ deficient mice have turned that idea on its head and instead identified RELM $\alpha$ as a critical regulator of Th2 immunity $[61,62]$. Using models of $S$. mansoni and $N$. brasiliensis infection, and schistosome egg-induced lung granuloma formation, RELM $\alpha$ was shown to limit Th2mediated immune pathologies by suppressing Th2 but not Th1 cytokine production. Importantly, this was mediated at least in part by a direct suppressive effect of RELM $\alpha$ on cytokine production by Th2 cells, as RELM $\alpha$ bound to Th2 cells and could exert this suppressive effect on T cells cultured alone in vitro [62]. RELM $\alpha$ could also be detected bound to other cells, including macrophages and DC (but not Th1 cells) suggesting other non $\mathrm{T}$ cell mediated functions for this molecule. It is worth noting that macrophages appeared to be only a minor source of RELM $\alpha$ in the lung and liver in these studies, perhaps explaining why Th2 responses remain normal during $S$. mansoni and $N$. brasiliensis infections in macrophage/neutrophil-specific IL-4R $\alpha$ deficient mice [79].

4.6.2. Arginase 1. Given that one of the downstream products of arginase-mediated L-arginine catabolism is a major component of collagen, it has been widely assumed that AAM $\Phi$ would promote the fibrotic pathologies associated with chronic Th2 stimuli. However, a recent elegant study using mice in which macrophages were deficient in arginase 1 expression has demonstrated that in fact, arginase 1 negatively regulates Th2 responses and actually suppresses Th2-mediated fibrosis [82]. In contrast to the effects of RELM $\alpha$ documented by Nair et al. [62], arginase 1 expression by macrophages impaired IFN $-\gamma$ production by T cells in addition to down regulating output of Th2 cytokines. $\mathrm{T}$ cell proliferation in the draining lymph node was also exaggerated in the absence of arginase 1 expression by macrophages [82]. Importantly, this data confirms an in vivo role for arginase 1 in proliferative suppression mediated by macrophages, but extends this to show that macrophages also exert an inhibitory effect on cytokine production. Critically, they demonstrate that macrophages exhibit an overall inhibitory effect on fibrosis during schistosomiasis via their production of arginase 1.

4.7. Summary of $A A M \Phi$ as Regulators of Th2 Immunity. One caveat to the conclusion that $\mathrm{AAM} \Phi$ have a critical function in the regulation of Th2 cytokines in both nematode and platyhelminth infections is the fact that Th2 generation in both the secondary lymphoid organs and the infection site (in which $А A M \Phi$ are present in greatest numbers) appeared unaffected by either the absence of IL- $4 \mathrm{R} \alpha$ signaling in macrophages or the depletion of macrophages, during $S$. mansoni, $N$. brasiliensis, and T. spiralis infection, and $H$. polygyrus and $N$. brasiliensis infection, respectively, [72, 73, $79,81]$. It cannot be ignored that because the role of macrophages in Th2 generation was not the main focus of these studies, the methodology for assessing the quality and quantity of the responses was not as thorough as that described for the studies on the function of RELM $\alpha$ [61, 62], arginase 1 [82], and $\mathrm{Ym} 1 / 2$ [113, 114]. It is possible though, that the removal of macrophages, or their alternative activation state, takes away both negative (RELM $\alpha$ and arginase 1) and positive (Ym1/2) regulatory signals such that the net effect on Th2 responses is nil. Whilst an in vivo role for arginase 1 production specifically by macrophages in Th2 regulation during schistosome infection cannot be denied, we await confirmation that RELM $\alpha$ and Ym1/2 production by these cells plays a major role in regulation of Th2 cytokine production in vivo. It may well be that "alternatively activated" DC and cells such as basophils play the greater role in Th2 response induction, maintenance, and 
regulation. With the recent recognition that basophils are a critical APC in promoting Th2 cell activation $[14,116]$, it would be of interest to know whether $\mathrm{Ym} 1 / 2$ is produced by these cells.

4.8. ААМФ as Cells That Repair Damage to the Host. Much of the data described above suggests that AAM $\Phi$ act as antiinflammatory down-regulatory cells, consistent with previously proposed functions for macrophages during helminth infection [117, 118]. Additionally AAM $\Phi$ are important sources of TGF- $\beta$ and IL-10 [60, 109, 119], as well PGE2 [91] and the IL-1 receptor antagonist $[119,120]$. The chemokine expression profile is also strongly associated with a noninflammatory role [58] and with specific down-regulation of key proinflammatory cytokines by IL- $4[6,120]$. It may seem counter-intuitive that an activated cell population manifests such profoundly suppressive features. However, this could be in part explained if one sees tissue repair or wound healing as a fundamental function associated with $А A M \Phi$. Effective tissue repair can only proceed if inflammation has been stopped $[119,121]$ and thus all these anti-inflammatory features may contribute to their role in repair. Early reviews on $А A M \Phi$ ascribed them a wound healing phenotype based on the production of arginase 1 [1] and angiogenic factors [1] as well as extracellular matrix components and fibronectin [122]. However, the specific role of IL-4/IL-13 in this healing phenotype versus glucocorticoids or IL-10, which the authors also considered alternative activators, was not immediately apparent. Furthermore, the relevance to helminth infection was not obvious.

Two recent papers have provided evidence that there is indeed very strong relevance to helminth infection. While investigating the kinetics of alternative activation in a model whereby B. malayi parasites are surgically implanted into the peritoneal cavity of mice, we noted that control animals who underwent only sham surgery exhibited transient upregulation of Ym1/2, RELM $\alpha$, and arginase 1 in a strictly IL$4 \mathrm{R} \alpha$ manner [23]. However, only when both the nematode and Th2 cells were present was this alternative activation response sustained. This suggested that the induction of the signature molecules of AAM $\Phi$ was in fact an innate response to direct injury. One feature all these helminths have in common is the capacity to injure tissue in the course of their migration through the host, providing a possible evolutionary explanation for the association of Th2 immunity and wound healing [123]. The strongest evidence to date from helminth models that $А A M \Phi$ have a combined anti-inflammatory/wound healing function is in a study of $S$. mansoni infection in mice that lack the IL-4R $\alpha$ specifically on macrophages and neutrophils and thus completely lack AAM $\Phi$ but have otherwise intact Th2 responses [79]. Following S. mansoni infection, these mice died from overwhelming inflammatory responses in the intestine and leakage of bacteria into the blood. Although not conclusive evidence, the data strongly suggests that in the absence of $A A M \Phi$, these mice were unable to repair the damage caused by egg migration through the intestinal wall. Further supporting a direct role for AAM $\Phi$ in wound healing, RELM $\alpha$ has angiogenic properties [124] and Ym1/2 has the ability to bind extracellular matrix [125]. The specific roles these proteins play in the complex orchestra for tissue repair and remodeling are still to be established.

\section{Summary}

Mast cells, basophils and eosinophils have long been considered the serious cellular players in the host response to helminth infection. Previously ignored, the macrophage is now taking center stage in this cellular family as one of the most important targets of Th2 immunity. This is fully appropriate when we consider that macrophages are frequently the most abundant cell type recruited to the site of helminth infection. However, it is only since the discovery of $А A M \Phi$ in vivo less than 10 years ago that a focus on these cells in helminth infection has begun. As a result, we have a long ways to go before we attain the extensive knowledge associated with CAM $\Phi$. The challenge is to define key roles for $\mathrm{AAM} \Phi$ while accepting that these may differ radically depending on infection stage, site, and parasite species. Macrophages are the workhorse of the immune system, and as such, can radically alter their phenotype to adapt to environmental signals $[55,59,60]$. In turn, they can actively regulate the inflammatory environment to which they are recruited or the tissues in which they reside. Using the tools available to modern scientists we can now begin to define the environmental codes that alter the $\mathrm{AAM} \Phi$ expression profile, understand the function of the products they produce, and decipher their communication with other cells. Recent discoveries that $\mathrm{AAM} \Phi$ are central to the regulation of host metabolism [126] mean this cross-talk is not only between cells of the immune system but with the entire organism. Unravelling this amazing complexity will keep helminth immunologists busy for years to come.

\section{Acknowledgments}

The first author is supported by the Medical Research Council UK. The second author receives funding from MRCUK, the European Union, Wellcome Trust \& Asthma UK. Many thanks to Dr. Dominik Ruckerl for critical review of the manuscript.

\section{References}

[1] M. Munder, K. Eichmann, and M. Modolell, "Alternative metabolic states in murine macrophages reflected by the nitric oxide synthase/arginase balance: competitive regulation by $\mathrm{CD}^{+} \mathrm{T}$ cells correlates with Th1/Th2 phenotype," Journal of Immunology, vol. 160, no. 11, pp. 5347-5354, 1998.

[2] M. G. Nair, D. W. Cochrane, and J. E. Allen, "Macrophages in chronic type 2 inflammation have a novel phenotype characterized by the abundant expression of Ym1 and Fizz1 that can be partly replicated in vitro," Immunology Letters, vol. 85, no. 2, pp. 173-180, 2003.

[3] G. Raes, P. de Baetselier, W. Noel, A. Beschin, F. Brombacher, and G. Hassanzadeh Gh, "Differential expression of FIZZ1 and Ym1 in alternatively versus classically activated 
macrophages," Journal of Leukocyte Biology, vol. 71, no. 4, pp. 597-602, 2002.

[4] M. Stein, S. Keshav, N. Harris, and S. Gordon, "Interleukin 4 potently enhances murine macrophage mannose receptor activity: a marker of alternative immunologic macrophage activation," Journal of Experimental Medicine, vol. 176, no. 1, pp. 287-292, 1992.

[5] A. G. Doyle, G. Herbein, L. J. Montaner, A. J. Minty, D. Caput, P. Ferrara, and S. Gordon, "Interleukin-13 alters the activation state of murine macrophages in vitro: comparison with interleukin-4 and interferon- $\gamma$," European Journal of Immunology, vol. 24, no. 6, pp. 1441-1445, 1994.

[6] P. Loke, M. G. Nair, D. Guiliano, J. Parkinson, M. L. Blaxter, and J. E. Allen, "IL-4 dependent alternatively-activated macrophages have a distinctive in vivo gene expression phenotype," BMC Immunology, vol. 3, article 7, 2002.

[7] G. Raes, L. Brys, B. K. Dahal, et al., "Macrophage galactosetype C-type lectins as novel markers for alternatively activated macrophages elicited by parasitic infections and allergic airway inflammation," Journal of Leukocyte Biology, vol. 77, no. 3, pp. 321-327, 2005.

[8] A. Varin and S. Gordon, "Alternative activation of macrophages: immune function and cellular biology," Immunobiology, vol. 214, no. 7, pp. 630-641, 2009.

[9] J. Van den Bossche, P. Bogaert, J. van Hengel, et al., "Alternatively activated macrophages engage in homotypic and heterotypic interactions through IL-4 and polyamineinduced E-cadherin/catenin complexes," Blood, vol. 114, no. 21, pp. 4664-4674, 2009.

[10] G. Raes, A. Beschin, G. H. Ghassabeh, and P. de Baetselier, "Alternatively activated macrophages in protozoan infections," Current Opinion in Immunology, vol. 19, no. 4, pp. 454-459, 2007.

[11] S. Gordon, "Alternative activation of macrophages," Nature Reviews Immunology, vol. 3, no. 1, pp. 23-35, 2003.

[12] J. S. Welch, L. Escoubet-Lozach, D. B. Sykes, K. Liddiard, D. R. Greaves, and C. K. Glass, "TH2 cytokines and allergic challenge induce Ym1 expression in macrophages by a STAT6-dependent mechanism," Journal of Biological Chemistry, vol. 277, no. 45, pp. 42821-42829, 2002.

[13] D. Voehringer, K. Shinkai, and R. M. Locksley, "Type 2 immunity reflects orchestrated recruitment of cells committed to IL-4 production," Immunity, vol. 20, no. 3, pp. 267277, 2004.

[14] J. G. Perrigoue, S. A. Saenz, M. C. Siracusa, et al., "MHC class II-dependent basophil-CD4 ${ }^{+} \mathrm{T}$ cell interactions promote $\mathrm{T}_{\mathrm{H}} 2$ cytokine-dependent immunity," Nature Immunology, vol. 10, no. 7, pp. 697-705, 2009.

[15] A. G. Zaretsky, J. J. Taylor, I. L. King, F. A. Marshall, M. Mohrs, and E. J. Pearce, "T follicular helper cells differentiate from Th2 cells in response to helminth antigens," Journal of Experimental Medicine, vol. 206, no. 5, pp. 991-999, 2009.

[16] D. Amsen, A. Antov, D. Jankovic, et al., "Direct regulation of gata3 expression determines the T helper differentiation potential of notch," Immunity, vol. 27, no. 1, pp. 89-99, 2007.

[17] S. J. Jenkins, G. Perona-Wright, and A. S. MacDonald, "Full development of Th2 immunity requires both innate and adaptive sources of CD154," Journal of Immunology, vol. 180, no. 12, pp. 8083-8092, 2008.

[18] B. Hausdorf, "Early evolution of the Bilateria," Systematic Biology, vol. 49, no. 1, pp. 130-142, 2000.

[19] M. L. Blaxter, "Nematoda: genes, genomes and the evolution of parasitism," Advances in Parasitology, vol. 54, pp. 101-195, 2003.
[20] P. J. Hotez and A. Kamath, "Neglected tropical diseases in Sub-Saharan Africa: review of their prevalence, distribution, and disease burden," PLoS Neglected Tropical Diseases, vol. 3, no. 8, article e412, 2009.

[21] M. Veldhoen, C. Uyttenhove, J. van Snick, et al., "Transforming growth factor- $\beta$ 'reprograms' the differentiation of $\mathrm{T}$ helper 2 cells and promotes an interleukin 9-producing subset," Nature Immunology, vol. 9, no. 12, pp. 1341-1346, 2008.

[22] D. Jankovic, M. C. Kullberg, C. G. Feng, et al., "Conventional T-bet ${ }^{+}$Foxp $3^{-}$Th1 cells are the major source of hostprotective regulatory IL-10 during intracellular protozoan infection," Journal of Experimental Medicine, vol. 204, no. 2, pp. 273-283, 2007.

[23] P. Loke, I. Gallagher, M. G. Nair, et al., "Alternative activation is an innate response to injury that requires $\mathrm{CD}^{+} \mathrm{T}$ cells to be sustained during chronic infection," Journal of Immunology, vol. 179, no. 6, pp. 3926-3936, 2007.

[24] J. Osborne and E. Devaney, "The L3 of Brugia induces a $\mathrm{T}_{\mathrm{h}} 2-$ polarized response following activation of an IL-4-producing CD4-CD8- $\alpha \beta$ T cell population," International Immunology, vol. 10, no. 10, pp. 1583-1590, 1998.

[25] S. Tawill, L. Le Goff, F. Ali, M. Blaxter, and J. E. Allen, "Both free-living and parasitic nematodes induce a characteristic Th2 response that is dependent on the presence of intact glycans," Infection and Immunity, vol. 72, no. 1, pp. 398-407, 2004.

[26] J. J. Reece, M. C. Siracusa, and A. L. Scott, "Innate immune responses to lung-stage helminth infection induce alternatively activated alveolar macrophages," Infection and Immunity, vol. 74, no. 9, pp. 4970-4981, 2006.

[27] J. C. Massacand, R. C. Stettler, R. Meier, et al., "Helminth products bypass the need for TSLP in Th2 immune responses by directly modulating dendritic cell function," Proceedings of the National Academy of Sciences of the United States of America, vol. 106, no. 33, pp. 13968-13973, 2009.

[28] T. A. Wynn, I. P. Oswald, I. A. Eltoum, et al., "Elevated expression of Th1 cytokines and nitric oxide synthase in the lungs of vaccinated mice after challenge infection with Schistosoma mansoni," Journal of Immunology, vol. 153, no. 11, pp. 5200-5209, 1994.

[29] J.-M. Grzych, E. Pearce, A. Cheever, et al., "ECG deposition is the major stimulus for the production of Th2 cytokines in murine schistomiasis mansoni," Journal of Immunology, vol. 146, no. 4, pp. 1322-1327, 1991.

[30] S. M. O’Neill, M. T. Brady, J. J. Callanan, et al., "Fasciola hepatica infection downregulates Th1 responses in mice," Parasite Immunology, vol. 22, no. 3, pp. 147-155, 2000.

[31] S. A. Toenjes and R. E. Kuhn, "The initial immune response during experimental cysticercosis is of the mixed Th1/Th2 type," Parasitology Research, vol. 89, no. 5, pp. 407-413, 2003.

[32] M. Rodriguez-Sosa, J. R. David, R. Bojalil, A. R. Satoskar, and L. I. Terrazas, "Cutting edge: susceptibility to the larval stage of the helminth parasite Taenia crassiceps is mediated by Th2 response induced via STAT6 signaling," Journal of Immunology, vol. 168, no. 7, pp. 3135-3139, 2002.

[33] M. Rodriguez-Sosa, R. Saavedra, E. P. Tenorio, L. E. Rosas, A. R. Satoskar, and L. I. Terrazas, "A STAT4-dependent Th1 response is required for resistance to the helminth parasite Taenia crassiceps," Infection and Immunity, vol. 72, no. 8, pp. 4552-4560, 2004.

[34] S. Dematteis, A. Baz, M. Rottenberg, C. Fernandez, A. Orn, and A. Nieto, "Antibody and Th1/Th2-type responses in $\mathrm{BALB} / \mathrm{c}$ mice inoculated with live or dead Echinococcus 
granulosus protoscoleces," Parasite Immunology, vol. 21, no. 1, pp. 19-26, 1999.

[35] J. E. Allen, O. Adjei, O. Bain, et al., "Of mice, cattle, and humans: the immunology and treatment of river blindness," PLoS Neglected Tropical Diseases, vol. 2, no. 4, article e217, 2008.

[36] M. Saeftel, M. Arndt, S. Specht, L. Volkmann, and A. Hoerauf, "Synergism of gamma interferon and interleukin5 in the control of murine filariasis," Infection and Immunity, vol. 71, no. 12, pp. 6978-6985, 2003.

[37] T. A. Wynn, R. W. Thompson, A. W. Cheever, and M. M. Mentink-Kane, "Immunopathogenesis of schistosomiasis," Immunological Reviews, vol. 201, pp. 156-167, 2004.

[38] T. A. Wynn, "Fibrotic disease and the TH1/TH2 paradigm," Nature Reviews Immunology, vol. 4, no. 8, pp. 583-594, 2004.

[39] J. Alonso-Trujillo, I. Rivera-Montoya, M. Rodriguez-Sosa, and L. I. Terrazas, "Nitric oxide contributes to host resistance against experimental Taenia crassiceps cysticercosis," Parasitology Research, vol. 100, no. 6, pp. 1341-1350, 2007.

[40] W. J. Dai, A. Waldvogel, T. Jungi, M. Stettler, and B. Gottstein, "Inducible nitric oxide synthase deficiency in mice increases resistance to chronic infection with Echinococcus multilocularis," Immunology, vol. 108, no. 2, pp. 238-244, 2003.

[41] W. J. Dai and B. Gottstein, "Nitric oxide-mediated immunosuppression following murine Echinococcus multilocularis infection," Immunology, vol. 97, no. 1, pp. 107-116, 1999.

[42] S. A. Linehan, P. S. Coulson, R. A. Wilson, et al., "IL-4 receptor signaling is required for mannose receptor expression by macrophages recruited to granulomata but not resident cells in mice infected with Schistosoma mansoni," Laboratory Investigation, vol. 83, no. 8, pp. 1223-1231, 2003.

[43] M. Hesse, M. Modolell, A. C. La Flamme, et al., "Differential regulation of nitric oxide synthase- 2 and arginase- 1 by type 1/type 2 cytokines in vivo: granulomatous pathology is shaped by the pattern of L-arginine metabolism," Journal of Immunology, vol. 167, no. 11, pp. 6533-6544, 2001.

[44] J. L. Reyes and L. I. Terrazas, "The divergent roles of alternatively activated macrophages in helminthic infections," Parasite Immunology, vol. 29, no. 12, pp. 609-619, 2007.

[45] R. J. Flynn, J. A. Irwin, M. Olivier, M. Sekiya, J. P. Dalton, and G. Mulcahy, "Alternative activation of ruminant macrophages by Fasciola hepatica," Veterinary Immunology and Immunopathology, vol. 120, no. 1-2, pp. 31-40, 2007.

[46] M. G. Nair, I. J. Gallagher, M. D. Taylor, et al., "Chitinase and Fizz family members are a generalized feature of nematode infection with selective upregulation of $\mathrm{Ym} 1$ and Fizz1 by antigen-presenting cells," Infection and Immunity, vol. 73, no. 1, pp. 385-394, 2005.

[47] R. Persaud, A. Wang, C. Reardon, and D. M. McKay, "Characterization of the immuno-regulatory response to the tapeworm Hymenolepis diminuta in the non-permissive mouse host," International Journal for Parasitology, vol. 37, no. 3-4, pp. 393-403, 2007.

[48] S. Donnelly, S. M. O’Neill, M. Sekiya, G. Mulcahy, and J. P. Dalton, "Thioredoxin peroxidase secreted by Fasciola hepatica induces the alternative activation of macrophages," Infection and Immunity, vol. 73, no. 1, pp. 166-173, 2005.

[49] T. R. Ramalingam, J. T. Pesce, F. Sheikh, et al., "Unique functions of the type II interleukin 4 receptor identified in mice lacking the interleukin 13 receptor $\alpha 1$ chain," Nature Immunology, vol. 9, no. 1, pp. 25-33, 2008.
[50] T. E. Sutherland, R. M. Maizels, and J. E. Allen, "Chitinases and chitinase-like proteins: potential therapeutic targets for the treatment of T-helper type 2 allergies," Clinical and Experimental Allergy, vol. 39, no. 7, pp. 943-955, 2009.

[51] I. N. Holcomb, R. C. Kabakoff, B. Chan, et al., "FIZZ1, a novel cysteine-rich secreted protein associated with pulmonary inflammation, defines a new gene family," The EMBO Journal, vol. 19, no. 15, pp. 4046-4055, 2000.

[52] C. M. Steppan, E. J. Brown, C. M. Wright, et al., "A family of tissue-specific resistin-like molecules," Proceedings of the National Academy of Sciences of the United States of America, vol. 98, no. 2, pp. 502-506, 2001.

[53] V. Bronte, P. Serafini, A. Mazzoni, D. M. Segal, and P. Zanovello, "L-arginine metabolism in myeloid cells controls T-lymphocyte functions," Trends in immunology, vol. 24, no. 6, pp. 302-306, 2003.

[54] M. B. Witte and A. Barbul, "Arginine physiology and its implication for wound healing," Wound Repair and Regeneration, vol. 11, no. 6, pp. 419-423, 2003.

[55] F. O. Martinez, S. Gordon, M. Locati, and A. Mantovani, "Transcriptional profiling of the human monocyte-tomacrophage differentiation and polarization: new molecules and patterns of gene expression," Journal of Immunology, vol. 177, no. 10, pp. 7303-7311, 2006.

[56] K. C. El Kasmi, J. E. Qualls, J. T. Pesce, et al., “Tolllike receptor-induced arginase 1 in macrophages thwarts effective immunity against intracellular pathogens," Nature Immunology, vol. 9, no. 12, pp. 1399-1406, 2008.

[57] C. Holscher, B. Arendse, A. Schwegmann, E. Myburgh, and F. Brombacher, "Impairment of alternative macrophage activation delays cutaneous leishmaniasis in nonhealing BALB/c mice," Journal of Immunology, vol. 176, no. 2, pp. 1115-1121, 2006.

[58] A. Mantovani, A. Sica, S. Sozzani, P. Allavena, A. Vecchi, and M. Locati, "The chemokine system in diverse forms of macrophage activation and polarization," Trends in Immunology, vol. 25, no. 12, pp. 677-686, 2004.

[59] R. D. Stout, C. Jiang, B. Matta, I. Tietzel, S. K. Watkins, and J. Suttles, "Macrophages sequentially change their functional phenotype in response to changes in microenvironmental influences," Journal of Immunology, vol. 175, no. 1, pp. 342349, 2005.

[60] K. J. Mylonas, M. G. Nair, L. Prieto-Lafuente, D. Paape, and J. E. Allen, "Alternatively activated macrophages elicited by helminth infection can be reprogrammed to enable microbial killing," Journal of Immunology, vol. 182, no. 5, pp. 30843094, 2009.

[61] J. T. Pesce, T. R. Ramalingam, M. S. Wilson, et al., "Retnla (relm $\alpha /$ fizz1) suppresses helminth-induced Th2type immunity," PLoS Pathogens, vol. 5, no. 4, Article ID e1000393, 2009.

[62] M. G. Nair, Y. Du, J. G. Perrigoue, et al., "Alternatively activated macrophage-derived RELM- $\alpha$ is a negative regulator of type 2 inflammation in the lung," Journal of Experimental Medicine, vol. 206, no. 4, pp. 937-952, 2009.

[63] R. J. Homer, Z. Zhu, L. Cohn, et al., "Differential expression of chitinases identify subsets of murine airway epithelial cells in allergic inflammation," American Journal of Physiology, vol. 291, no. 3, pp. L502-L511, 2006.

[64] M. A. Hoeve, K. J. Mylonas, K. J. Fairlie-Clarke, S. M. Mahajan, J. E. Allen, and A. L. Graham, "Plasmodium chabaudi limits early Nippostrongylus brasiliensis-induced 
pulmonary immune activation and Th2 polarization in coinfected mice," BMC Immunology, vol. 10, no. 60, 2009.

[65] D. Artis, M. L. Wang, S. A. Keilbaugh, et al., "RELM $\beta /$ FIZZ2 is a goblet cell-specific immune-effector molecule in the gastrointestinal tract," Proceedings of the National Academy of Sciences of the United States of America, vol. 101, no. 37, pp. 13596-13600, 2004.

[66] T. A. Reese, H.-E. Liang, A. M. Tager, et al., "Chitin induces accumulation in tissue of innate immune cells associated with allergy," Nature, vol. 447, no. 7140, pp. 92-96, 2007.

[67] F. C. Fang and C. F. Nathan, "Man is not a mouse: reply," Journal of Leukocyte Biology, vol. 81, no. 3, p. 580, 2007.

[68] A. Erdely, D. Kepka-Lenhart, M. Clark, et al., "Inhibition of phosphodiesterase 4 amplifies cytokine-dependent induction of arginase in macrophages," American Journal of Physiology, vol. 290, no. 3, pp. L534-L539, 2006.

[69] S. Babu, V. Kumaraswami, and T. B. Nutman, "Alternatively activated and immunoregulatory monocytes in human filarial infections," Journal of Infectious Diseases, vol. 199, no. 12, pp. 1827-1837, 2009.

[70] A. P. Bussink, D. Speijer, J. M. F. G. Aerts, and R. G. Boot, "Evolution of mammalian chitinase(-like) members of family 18 glycosyl hydrolases," Genetics, vol. 177, no. 2, pp. 959-970, 2007.

[71] C. G. Lee, D. Hartl, G. R. Lee, et al., "Role of breast regression protein 39 (BRP-39)/chitinase 3-like-1 in Th2 and IL-13-induced tissue responses and apoptosis," Journal of Experimental Medicine, vol. 206, no. 5, pp. 1149-1166, 2009.

[72] R. M. Anthony, J. F. Urban, F. Alem, et al., "Memory TH2 cells induce alternatively activated macrophages to mediate protection against nematode parasites," Nature Medicine, vol. 12, no. 8, pp. 955-960, 2006.

[73] A. Zhao, J. F. Urban Jr., R. M. Anthony, et al., "Th2 cytokine-induced alterations in intestinal smooth muscle function depend on alternatively activated macrophages," Gastroenterology, vol. 135, no. 1, pp. 217-225, 2008.

[74] H. Nakanishi, Y. Horii, K. Terashima, and K. Fujita, "Effect of macrophage blockade on the resistance to a primary Brugia pahangi infection of female BALB/c mice," Tropical Medicine and Parasitology, vol. 40, no. 1, pp. 75-76, 1989.

[75] U. R. Rao, A. C. Vickery, B. H. Kwa, J. K. Nayar, and D. Subrahmanyam, "Effect of carrageenan on the resistance of congenitally athymic nude and normal BALB/c mice to infective larvae of Brugia malayi," Parasitology Research, vol. 78, no. 3, pp. 235-240, 1992.

[76] J. E. Simons, M. E. Rothenberg, and R. A. Lawrence, "Eotaxin-1-regulated eosinophils have a critical role in innate immunity against experimental Brugia malayi infection," European Journal of Immunology, vol. 35, no. 1, pp. 189-197, 2005.

[77] C. Martin, L. Le Goff, M.-N. Ungeheuer, P. N. Vuong, and O. Bain, "Drastic reduction of a filarial infection in eosinophilic interleukin-5 transgenic mice," Infection and Immunity, vol. 68, no. 6, pp. 3651-3656, 2000.

[78] D. Voehringer, N. van Rooijen, and R. M. Locksley, "Eosinophils develop in distinct stages and are recruited to peripheral sites by alternatively activated macrophages," Journal of Leukocyte Biology, vol. 81, no. 6, pp. 1434-1444, 2007.

[79] D. R. Herbert, C. Holscher, M. Mohrs, et al., "Alternative macrophage activation is essential for survival during schistosomiasis and downmodulates $\mathrm{T}$ helper 1 responses and immunopathology," Immunity, vol. 20, no. 5, pp. 623-635, 2004.
[80] J. F. Urban Jr., N. Noben-Trauth, L. Schopf, K. B. Madden, and F. D. Finkelman, "Cutting edge: IL-4 receptor expression by non-bone marrow-derived cells is required to expel gastrointestinal nematode parasites," Journal of Immunology, vol. 167, no. 11, pp. 6078-6081, 2001.

[81] C. E. Michels, H. E. Scales, K. A. Saunders, et al., "Neither interleukin-4 receptor $\alpha$ expression on $\mathrm{CD}^{+} \mathrm{T}$ cells, or macrophages and neutrophils is required for protective immunity to Trichinella spiralis," Immunology, vol. 128, no. 1 part 2, pp. e385-e394, 2009.

[82] J. T. Pesce, T. R. Ramalingam, M. M. Mentink-Kane, et al., "Arginase-1-expressing macrophages suppress Th2 cytokinedriven inflammation and fibrosis," PLoS Pathogens, vol. 5, no. 4, Article ID e1000371, 2009.

[83] G. R. Thomas, M. McCrossan, and M. E. Selkirk, "Cytostatic and cytotoxic effects of activated macrophages and nitric oxide donors on Brugia malayi," Infection and Immunity, vol. 65, no. 7, pp. 2732-2739, 1997.

[84] T. Kanazawa, H. Asahi, H. Hata, K. Mochida, N. Kagei, and M. J. Stadecker, "Arginine-dependent generation of reactive nitrogen intermediates is instrumental in the in vitro killing of protoscoleces of Echinococcus multilocularis by activated macrophages," Parasite Immunology, vol. 15, no. 11, pp. 619623, 1993.

[85] M. Capron and A. Capron, "Immunoglobulin E and effector cells in schistosomiasis," Science, vol. 264, no. 5167, pp. 18761877, 1994.

[86] D. Piedrafita, J. C. Parsons, R. M. Sandeman, et al., "Antibody-dependent cell-mediated cytotoxicity to newly excysted juvenile Fasciola hepatica in vitro is mediated by reactive nitrogen intermediates," Parasite Immunology, vol. 23, no. 9, pp. 473-482, 2001.

[87] J. MacMicking, Q.-W. Xie, and C. Nathan, "Nitric oxide and macrophage function," Annual Review of Immunology, vol. 15, pp. 323-350, 1997.

[88] N. Patel, T. Kreider, J. F. Urban Jr., and W. C. Gause, "Characterisation of effector mechanisms at the host:parasite interface during the immune response to tissue-dwelling intestinal nematode parasites," International Journal for Parasitology, vol. 39, no. 1, pp. 13-21, 2009.

[89] P. Loke, A. S. MacDonald, A. Robb, R. M. Maizels, and J. E. Allen, "Alternatively activated macrophages induced by nematode infection inhibit proliferation via cell-to-cell contact," European Journal of Immunology, vol. 30, no. 9, pp. 2669-2678, 2000.

[90] J. E. Allen, R. A. Lawrence, and R. M. Maizels, "APC from mice harbouring the filarial nematode, Brugia malayi, prevent cellular proliferation but not cytokine production," International Immunology, vol. 8, no. 1, pp. 143-151, 1996.

[91] M. Rodriguez-Sosa, A. R. Satoskar, R. Calderon, et al., "Chronic helminth infection induces alternatively activated macrophages expressing high levels of CCR5 with low interleukin-12 production and Th2-biasing ability," Infection and Immunity, vol. 70, no. 7, pp. 3656-3664, 2002.

[92] L. I. Terrazas, D. Montero, C. A. Terrazas, J. L. Reyes, and M. Rodriguez-Sosa, "Role of the programmed Death-1 pathway in the suppressive activity of alternatively activated macrophages in experimental cysticercosis," International Journal for Parasitology, vol. 35, no. 13, pp. 1349-1358, 2005.

[93] P. Smith, C. M. Walsh, N. E. Mangan, et al., "Schistosoma mansoni worms induce anergy of T cells via selective upregulation of programmed death ligand 1 on macrophages," Journal of Immunology, vol. 173, no. 2, pp. 1240-1248, 2004. 
[94] M. D. Taylor, A. Harris, M. G. Nair, R. M. Maizels, and J. E. Allen, "F4/80 $0^{+}$alternatively activated macrophages control $\mathrm{CD}^{+} \mathrm{T}$ cell hyporesponsiveness at sites peripheral to filarial infection," Journal of Immunology, vol. 176, no. 11, pp. 69186927, 2006.

[95] L. Brys, A. Beschin, G. Raes, et al., "Reactive oxygen species and 12/15-lipoxygenase contribute to the antiproliferative capacity of alternatively activated myeloid cells elicited during helminth infection," Journal of Immunology, vol. 174, no. 10, pp. 6095-6104, 2005.

[96] M. Hesse, C. A. Piccirillo, Y. Belkaid, et al., "The pathogenesis of schistosomiasis is controlled by cooperating IL-10producing innate effector and regulatory T cells," Journal of Immunology, vol. 172, no. 5, pp. 3157-3166, 2004.

[97] J. Osborne and E. Devaney, "Interleukin-10 and antigenpresenting cells actively suppress Th1 cells in BALB/c mice infected with the filarial parasite Brugia pahangi," Infection and Immunity, vol. 67, no. 4, pp. 1599-1605, 1999.

[98] S. Mandruzzato, S. Solito, E. Falisi, et al., "IL4R $\alpha^{+}$myeloidderived suppressor cell expansion in cancer patients," Journal of Immunology, vol. 182, pp. 6562-6568, 2009.

[99] B.-S. Choi, I. C. Martinez-Falero, C. Corset, et al., "Differential impact of L-arginine deprivation on the activation and effector functions of T cells and macrophages," Journal of Leukocyte Biology, vol. 85, no. 2, pp. 268-277, 2009.

[100] S. Kusmartsev, Y. Nefedova, D. Yoder, and D. I. Gabrilovich, "Antigen-specific inhibition of $\mathrm{CD}^{+} \mathrm{T}$ cell response by immature myeloid cells in cancer is mediated by reactive oxygen species," Journal of Immunology, vol. 172, no. 2, pp. 989-999, 2004.

[101] R. A. O'Connor, J. S. Jenson, and E. Devaney, "NO contributes to proliferative suppression in a murine model of filariasis," Infection and Immunity, vol. 68, no. 11, pp. 61016107, 2000.

[102] R. M. Maizels and M. Yazdanbakhsh, "Immune regulation by helminth parasites: cellular and molecular mechanisms," Nature Reviews Immunology, vol. 3, no. 9, pp. 733-744, 2003.

[103] E. A. Ottesen, P. F. Weller, and L. Heck, "Specific cellular immune unresponsiveness in human filariasis," Immunology, vol. 33, no. 3, pp. 413-421, 1977.

[104] E. A. Ottesen, R. A. Hiatt, A. W. Cheever, Z. R. Sotomayor, and F. A. Neva, "The acquisition and loss of antigen-specific cellular immune responsiveness in acute and chronic schistosomiasis in man," Clinical and Experimental Immunology, vol. 33, no. 1, pp. 38-47, 1978.

[105] W. F. Piessens, P. B. McGreevy, P. W. Piessens, et al., "Immune responses in human infections with Brugia malayi. Specific cellular unresponsiveness to filarial antigens," Journal of Clinical Investigation, vol. 65, no. 1, pp. 172-179, 1980.

[106] M. C. Siracusa, J. J. Reece, J. F. Urban Jr., and A. L. Scott, "Dynamics of lung macrophage activation in response to helminth infection," Journal of Leukocyte Biology, vol. 84, no. 6, pp. 1422-1433, 2008.

[107] N. Mejri and B. Gottstein, "Intraperitoneal Echinococcus multilocularis infection in C57BL/6 mice affects CD40 and B7 costimulator expression on peritoneal macrophages and impairs peritoneal T cell activation," Parasite Immunology, vol. 28, no. 8, pp. 373-385, 2006.

[108] P. Loke and J. P. Allison, "PD-L1 and PD-L2 are differentially regulated by Th1 and Th2 cells," Proceedings of the National Academy of Sciences of the United States of America, vol. 100, no. 9, pp. 5336-5341, 2003.
[109] P. Loke, A. S. MacDonald, and J. E. Allen, "Antigenpresenting cells recruited by Brugia malayi induce Th2 differentiation of naive CD4 ${ }^{+} \mathrm{T}$ cells," European Journal of Immunology, vol. 30, no. 4, pp. 1127-1135, 2000.

[110] A. D. Straw, A. S. MacDonald, E. Y. Denkers, and E. J. Pearce, "CD154 plays a central role in regulating dendritic cell activation during infections that induce TH1 or TH2 responses," Journal of Immunology, vol. 170, no. 2, pp. 727734, 2003.

[111] G. Perona-Wright, S. J. Jenkins, and A. S. MacDonald, "Dendritic cell activation and function in response to Schistosoma mansoni," International Journal for Parasitology, vol. 36, no. 6, pp. 711-721, 2006.

[112] A. Balic, Y. Harcus, M. J. Holland, and R. M. Maizels, "Selective maturation of dendritic cells by Nippostrongylus brasiliensis-secreted proteins drives Th2 immune responses," European Journal of Immunology, vol. 34, no. 11, pp. 30473059, 2004.

[113] M. Arora, L. Chen, M. Paglia, et al., "Simvastatin promotes Th2-type responses through the induction of the chitinase family member Ym1 in dendritic cells," Proceedings of the National Academy of Sciences of the United States of America, vol. 103, no. 20, pp. 7777-7782, 2006.

[114] Y. Cai, R. K. Kumar, J. Zhou, P. S. Foster, and D. C. Webb, "Ym1/2 promotes Th2 cytokine expression by inhibiting 12/15(S)-lipoxygenase: identification of a novel pathway for regulating allergic inflammation.," Journal of Immunology, vol. 182, no. 9, pp. 5393-5399, 2009.

[115] A. Nencioni, S. Wesselborg, and P. Brossart, "Role of peroxisome proliferator-activated receptor $\gamma$ and its ligands in the control of immune responses," Critical Reviews in Immunology, vol. 23, no. 1-2, pp. 1-13, 2003.

[116] C. L. Sokol, N.-Q. Chu, S. Yu, S. A. Nish, T. M. Laufer, and R. Medzhitov, "Basophils function as antigen-presenting cells for an allergen-induced T helper type 2 response," Nature Immunology, vol. 10, no. 7, pp. 713-720, 2009.

[117] J. E. Allen and P. Loke, "Divergent roles for macrophages in lymphatic filariasis," Parasite Immunology, vol. 23, no. 7, pp. 345-352, 2001.

[118] P. O. Flores Villanueva, T. S. Harris, D. E. Ricklan, and M. J. Stadecker, "Macrophages from schistosomal egg granulomas induce unresponsiveness in specific cloned Th1 lymphocytes in vitro and down-regulate schistosomal granulomatous disease in vivo," Journal of Immunology, vol. 152, no. 4, pp. 1847-1855, 1994.

[119] S. Goerdt and C. E. Orfanos, "Other functions, other genes: alternative activation of antigen- presenting cells," Immunity, vol. 10, no. 2, pp. 137-142, 1999.

[120] M. J. Fenton, J. A. Buras, and R. P. Donnelly, "IL-4 reciprocally regulates IL-1 and IL-1 receptor antagonist expression in human monocytes," Journal of Immunology, vol. 149, no. 4, pp. 1283-1288, 1992.

[121] S. A. Eming, T. Krieg, and J. M. Davidson, "Inflammation in wound repair: molecular and cellular mechanisms," Journal of Investigative Dermatology, vol. 127, no. 3, pp. 514-525, 2007.

[122] A. Gratchev, P. Guillot, N. Hakiy, et al., "Alternatively activated macrophages differentially express fibronectin and its splice variants and the extracellular matrix protein $\beta$ IGH3," Scandinavian Journal of Immunology, vol. 53, no. 4, pp. 386-392, 2001.

[123] A. L. Graham, J. E. Allen, and A. F. Read, "Evolutionary causes and consequences of immunopathology," Annual 
Review of Ecology, Evolution, and Systematics, vol. 36, pp. 373397, 2005.

[124] X. Teng, D. Li, H. C. Champion, and R. A. Johns, "FIZZ1/RELM $\alpha$, a novel hypoxia-induced mitogenic factor in lung with vasoconstrictive and angiogenic properties," Circulation Research, vol. 92, no. 10, pp. 1065-1067, 2003.

[125] S.-I. Hung, A. C. Chang, I. Kato, and N.-C. A. Chang, "Transient expression of Ym1, a heparin-binding lectin, during developmental hematopoiesis and inflammation," Journal of Leukocyte Biology, vol. 72, no. 1, pp. 72-82, 2002.

[126] J. I. Odegaard, R. R. Ricardo-Gonzalez, M. H. Goforth, et al., "Macrophage-specific PPAR $\gamma$ controls alternative activation and improves insulin resistance," Nature, vol. 447, no. 7148, pp. 1116-1120, 2007. 

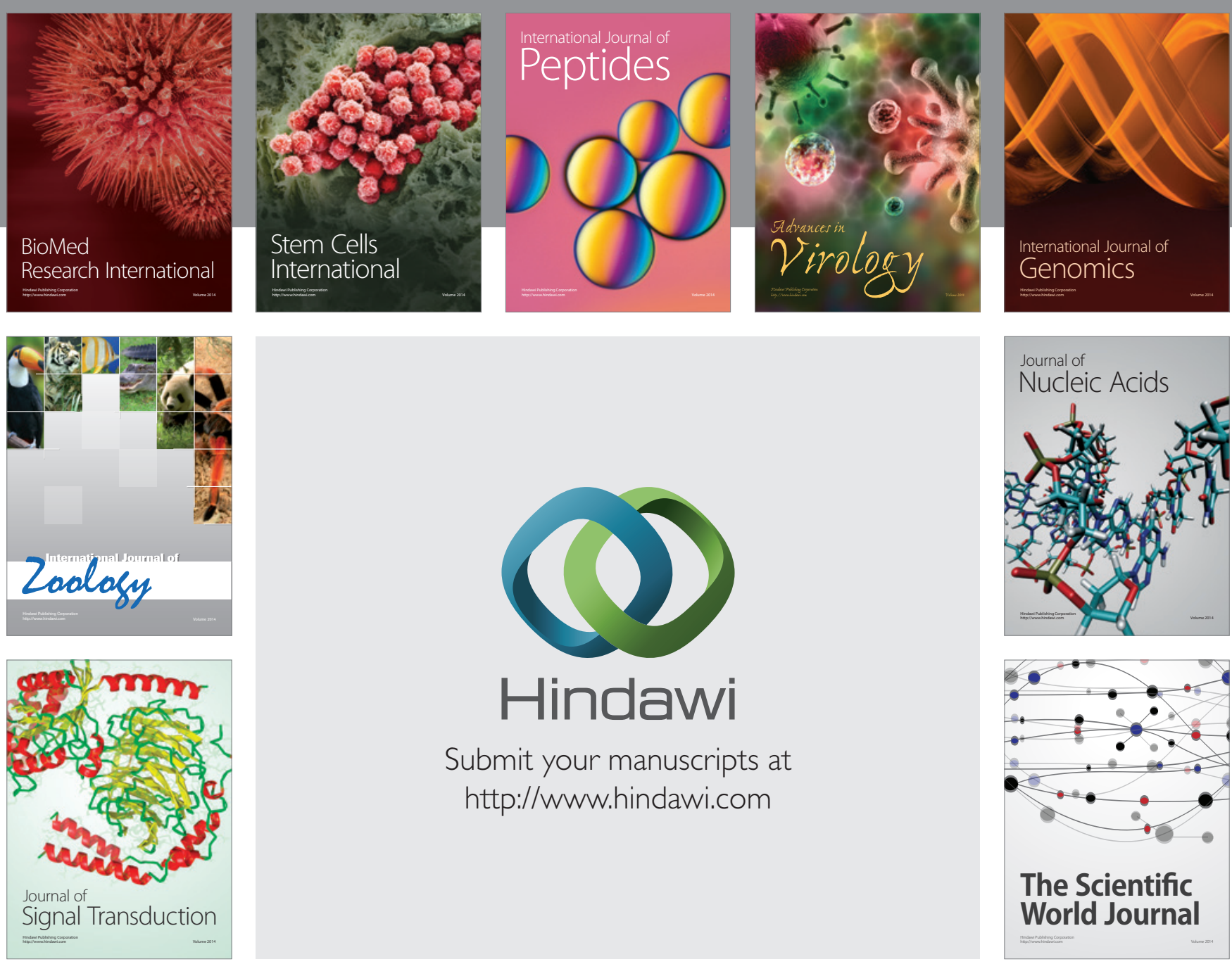

Submit your manuscripts at

http://www.hindawi.com
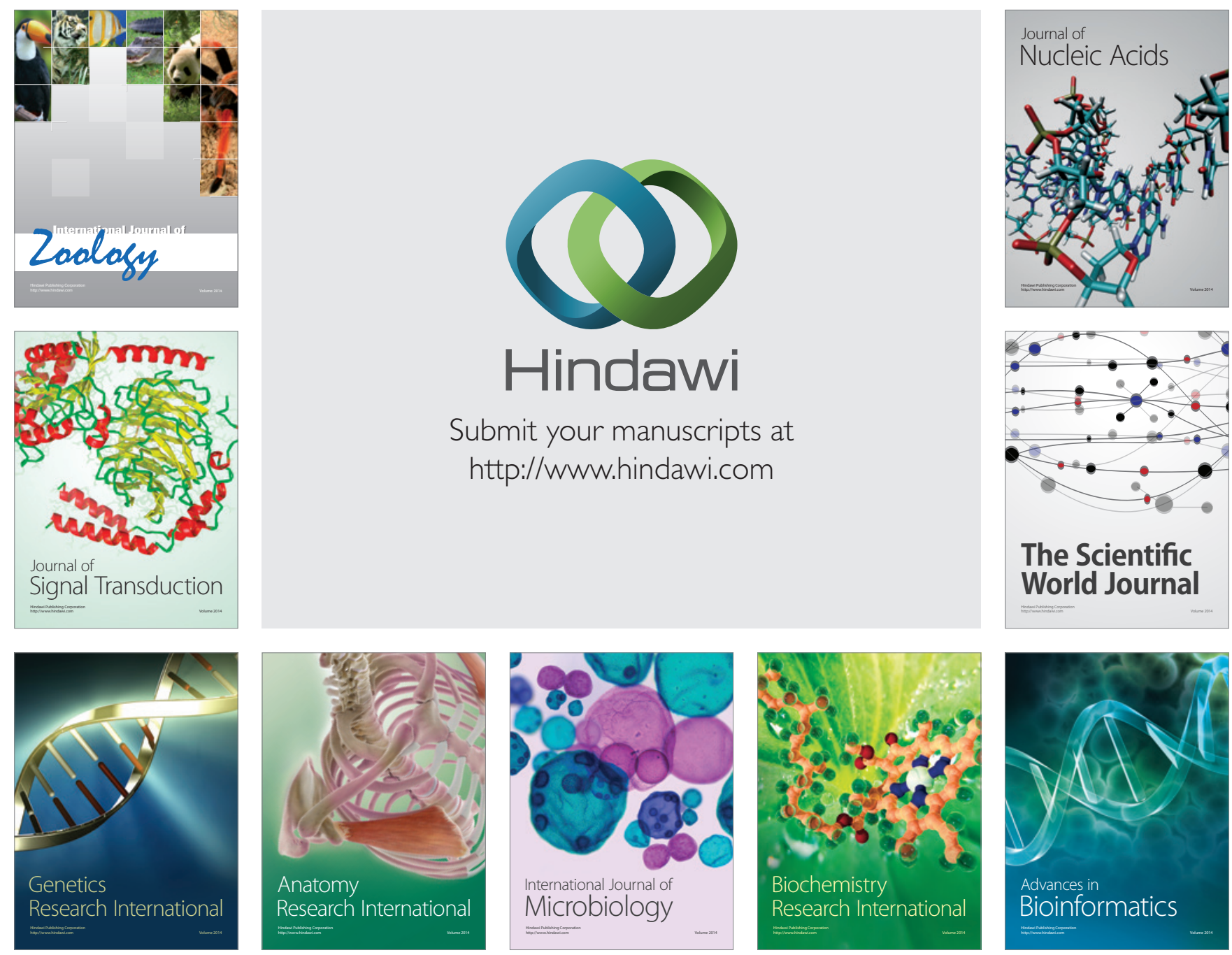

The Scientific World Journal
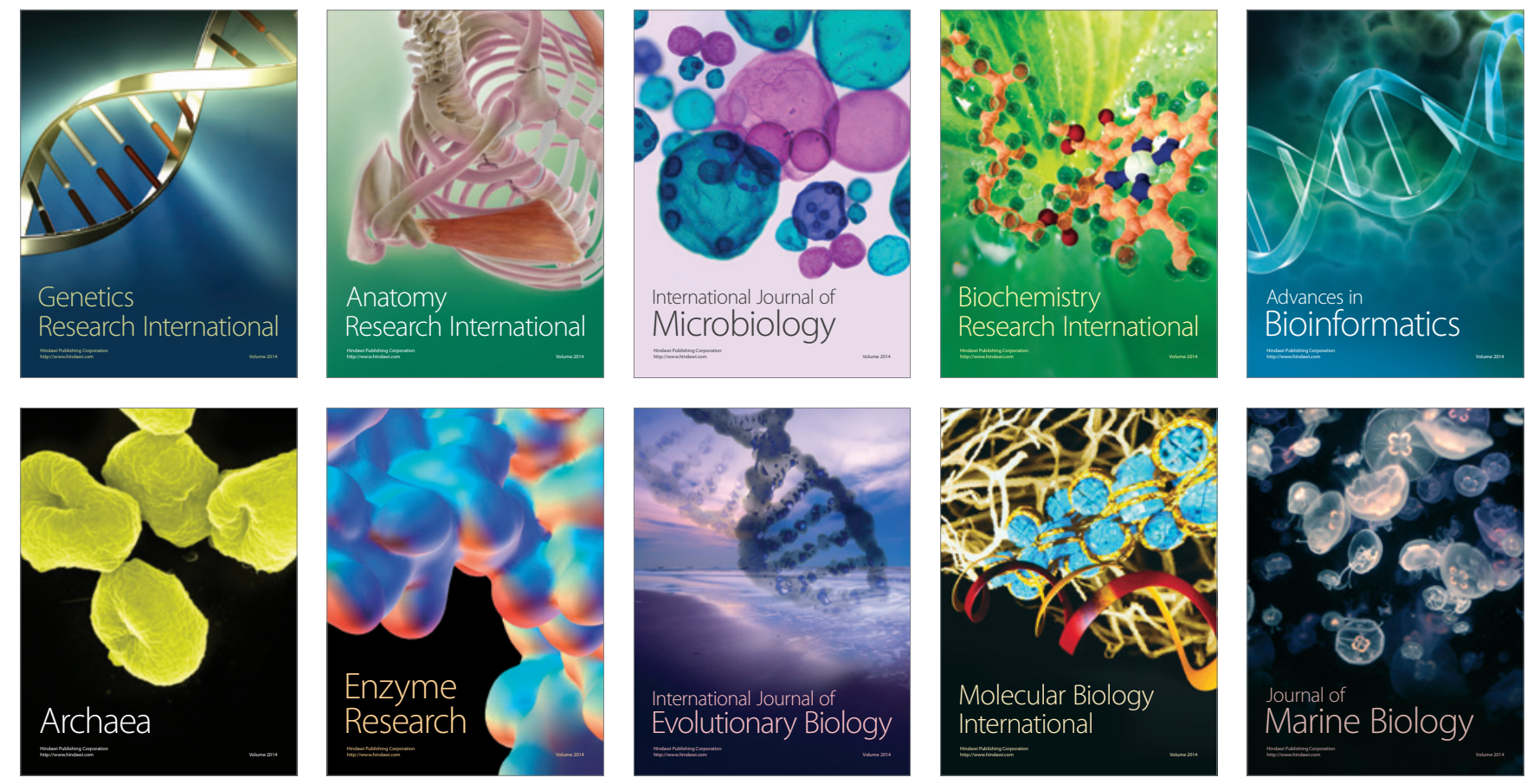